\title{
Ceftriaxone-Induced Fatal Anaphylaxis Shock at an Emergency Department: A Case Report
}

\author{
Ethar Abdelmageed Imam ${ }^{1}$ and Mohamed Izham Mohamed Ibrahim ${ }^{2}$ \\ ${ }^{1}$ Department of Pharmacy, Security Forces Hospital, Makkah, KSA \\ ${ }^{2}$ Clinical Pharmacy and Practice Section, College of Pharmacy, Qatar University, Doha, QATAR
}

Received: 21 July 2017;
Accepted: 9 September 2017
*Correspondence to:

Mohamed Izham Mohamed Ibrahim, PhD, Professor of Social and Administrative Pharmacy, Clinical Pharmacy and Practice Section, College of Pharmacy, Qatar University, Al Tarfa St, P.O. Box 2713, Doha, QATAR. Email:mohamedizham@qu.edu.qa

Copyright: $\odot$ the author(s),publisher and licensee Indian Academy of Pharmacists. This is an openaccess article distributed under the terms of the Creative Commons Attribution Non-Commercial License, which permits unrestricted non-commercial use, distribution, and reproduction in any medium, provided the original work is properly cited.

\begin{abstract}
Anaphylaxis in adults caused by medications such as antibiotics are quite common. To best of our knowledge, the case of anaphylaxis caused by ceftriaxone in our hospital and clinical practice is rare and especially among Saudi patients. A 31-years old Arab female patient was admitted to the emergency (ER) department due to influenza symptoms. Patient was suspected having pneumonia after examination. History indicated that she did not have penicillin allergy in the past, no history of any other concomitant medications, and no other comorbidities. Patient was febrile. At ER department, she was given ceftriaxone $1 \mathrm{~g}$ intravenous (IV) and within $15 \mathrm{~min}$ the patient started to complain from shortness of breath, bronchospasm and developed irregularity of the vital signs. Patient was suspected experiencing anaphylactic shock. Ceftriaxone was discontinued. Aggressive management started immediately; patient was given oxygen, IM adrenaline, IV hydrocortisone, IV bolus of normal saline, IV ringer lactate, IV pheniramine, and IV ranitidine. Tepid water sponging was provided to control the fever. After resuscitative treatment, patient was stabilized and the vital signs were good. The patient then was moved out to the medical ward. Health care professionals at the Emergency Department should be mindful of the anaphylaxis possibility with patient receiving antibiotics in the cephalosporin group.
\end{abstract}

Key words: Anaphylactic Shock, Ceftriaxone, Hypersensitivity, Resuscitative Treatment, Penicillin

\section{INTRODUCTION}

Ceftriaxone is a $3^{\text {rd }}$ generation cephalosporin antibiotic, commonly used to treat infections, both g-positive and -negative bacteria. It can cause a range of hypersensitivity reactions and should be contraindicated in patients with known hypersensitivity. ${ }^{[1]}$ Incidence of anaphylaxis caused by ceftriaxone is rare. Anaphylaxis could be caused by drugs such as antibiotics, opioids, non-steroidal anti-inflammatory drugs (NSAIDs) and muscle relaxants. Sign and symptoms of anaphylaxis are variable and can range from mild skin lesion to fatal reaction. It affects different organs and its most severe form results in anaphylaxis. If patients have previous experience of hypersensitivity reactions to penicillin and other beta lactam antibacterial agents, they might have greater risk of hypersensitivity to Ceftriaxone.

Case Presentation

A 31-years old Arab female patient was admitted to the emergency (ER) department due to influenza symptoms. She weighs $65 \mathrm{~kg}$ and $165 \mathrm{~cm}$ in height. Based on the 
examination, patient was suspected having pneumonia. She has history of celiac disease. History taking showed that she does not have penicillin allergy in the past, no history of any other concomitant medications, and no other comorbidities. Upon admission, patient was febrile with 38 degree Celsius. At ER department she was given ceftriaxone $1 \mathrm{~g}$ intravenous (IV) and within $15 \mathrm{~min}$ the patient started to complain from shortness of breath and bronchospasm started with severe drop in the blood pressure (BP); the vital signs i.e. BP was $65 / 52 \mathrm{mmHg}$, normal blood oxygen saturation levels (SpO2) was 87\%, and respiratory rate (RR) was $31 / \mathrm{min}$. No sensitivity test was taken prior to the administration of the medicine. Anaphylactic reaction was suspected.

Action: Ceftriaxone was stopped immediately. Aggressive management started immediately with resuscitative treatment. Patient was put on high flow oxygen via face mask and was administered the following: injection (Inj.) adrenaline 500 micrograms intramuscular (IM) $(0.5 \mathrm{~mL}$ ), Inj. hydrocortisone slow IV $200 \mathrm{mg}$, ringer lactate IV, Inj. pheniramine $1 \mathrm{mg} / \mathrm{kg}$ slow IV and Inj ranitidine $1 \mathrm{mg} / \mathrm{kg}$ IV along with two boluses of normal saline. She was given tepid water sponging to control the fever.

Evaluation: On the same day, after 6 hrs of resuscitative treatment, patient had pulse rate of $82 / \mathrm{min}$; BP $100 / 71$ $\mathrm{mmHg}$ and RR $21 / \mathrm{min}$. Patients laboratory investigations showed raised monocyte count:

Monocyte $\%=13.70 \%$ (normal range: $0.00-12.00$ )

Monocytes $=1.1610 \mathrm{e} 3 / \mathrm{uL}$ (normal range: $0.00-0.90)$.

Other laboratory values:

Vitamin D $(25-\mathrm{OH})=6.9 \mathrm{ng} / \mathrm{mL}$ (normal range: $>30.0$ 70.0), it shows severe drop in the level.

Creatine kinase $\mathrm{MB}$ isoenzyme-CK-MB $=0.3 \mathrm{U} / \mathrm{L}$ (normal range: $3.6-4.9$ )

Patient was closely monitored, then discharged to the medical ward with no further issues.

\section{DISCUSSION}

Cephalosporins are among the most commonly-used antibiotics in the treatment of routine infections and their use is increasing over time. ${ }^{[2]}$ Ceftriaxone is a broad-spectrum cephalosporin antibiotic for IV or IM administration. Ceftriaxone was completely absorbed following IM administration with mean maximum plasma concentrations occurring between 2 and $3 \mathrm{~h}$ post-dose. Multiple IV or IM doses ranging from 0.5 to $2 \mathrm{~g}$ at 12 to 24 -h intervals resulted in $15 \%$ to $36 \%$ accumulation of Ceftriaxone above single dose values ${ }^{[3]}$ Ceftriaxone is reversibly bound to human plasma proteins and crosses the blood placenta barrier.

Ceftriaxone induced anaphylaxis is a rare case but the incidence of hypersensitivity skin reactions was reported between 1 to $3 \%{ }^{[4]}$ Cephalosporin reactions can be divided into in two categories: (1) immediate which develop within $1 \mathrm{~h}$ after drug administration, and (2) nonimmediate which develop after $1 \mathrm{~h}$ of drug administration. ${ }^{[5]}$ Anaphylaxis can happen in patients with immunoglobulin E-mediated allergy ${ }^{[6,7]}$ Anaphylaxis is an acute life threatening reaction. Antibiotic skin testing is not normally done in a patients without a history of allergy including food allergy. Patients planned to take antibiotic therapy especially intravenous route or intramuscular should apply the penicillin skin test. If patient sensitive to penicillin thus, there is cross sensitivity with cephalosporin to develop allergy. Fast recognition and appropriate aggressive treatment using the Airway, Breathing, Circulation, Disability, and Exposure (ABCDE) approach are important for the successful management of anaphylaxis. ${ }^{[8]}$ Patients must constantly be observed and followed up. Healthcare professionals are encouraged to refer to international guidelines e.g. UK guidelines for emergency treatment of anaphylactic reactions for emergency treatment of anaphylaxis ${ }^{[8]}$ and other useful websites e.g. www.resus.org.uk, www.bsaci.org. www.eaaci.net, www.cochrane.org. www.bestbets.org. Patient need to know the allergen responsible, know how to avoid situations and be able to recognize the early symptoms of anaphylaxis.

\section{CONCLUSION}

An antibiotic medication allergy is a harmful reaction to an antibiotic. All antibiotics can produce allergy varying between patients. Each antibiotic can be tested for allergy. Usually patients stating an allergy to any medication or food or suffering from asthma or disease exacerbated by allergies. Skin test should be carried out. Healthcare providers should be careful in using cephalosporin and penicillin group antibiotics. Patient education is important. ADR cases should be reported to the hospital and national pharmacovigilance center.

\section{Acknowledgement: None}

Competing interests: None declared 
Ceftriaxone-induced fatal anaphylaxis shock

\section{Funding: None}

Abbreviation: None

\section{REFERENCES}

1. Up-to-date. Cephalosporin allergy: clinical manifestation and diagnosis. Available from: https://www.uptodate.com/contents/cephalosporin-allergyclinical-manifestations-and-diagnosis.

2. Ferech M, Coenen S, Malhotra-Kumar S, et al. European Surveillance of Antimicrobial Consumption (ESAC): outpatient antibiotic use in Europe. J
Antimicrobial Chemotherapy. 2006;58(2):401-7.

3. Drugs.com. Ceftriaxone. Available from: https://www.drugs.com/pro/ ceftriaxone.html.

4. Saritas A, Erbas M, Gonen I, Candar M, Ozturk O, Kandis H, et al. Asystole after the first dose of ceftriaxone. Am J Emergency Med. 2012;30(7):1321-e3-4.

5. Romano A, Demoly P. Recent advances in the diagnosis of drug allergy. Current Opinion Allergy Clinical Immunol. 2007;7(4):299-303.

6. Norrby SR. Side effects of cephalosporins. Drugs. 1987;34(2):105-20.

7. Guéant JL, Guéant-Rodriguez RM, Viola M, et al. IgE-mediated hypersensitivity to cephalosporins. Current Pharm Des. 2006;12(26):3335-45.

8. UK Resuscitation Council (UK). Emergency treatment of anaphylactic reactions: Guidelines for healthcare providers. 2016.(assessed 2,2017)

Cite this article as: Imam EA and Ibrahim MIM. Ceftriaxone-Induced Fatal Anaphylaxis Shock at an Emergency Department: A Case Report. J Pharm Pract Community Med. 2017;3(4):299-301. 